\title{
Contribuiçóes da Terapia Ocupacional no apoio e assistência a familiares de pessoas com transtornos mentais
}

\author{
Roberta Pereira Casagrande ${ }^{a}$, Milton Carlos Mariotti ${ }^{b}$, Mônica de Macedo Cardoso ${ }^{b}$ \\ ${ }^{a}$ Curso de Terapia Ocupacional, Universidade Federal do Paraná - UFPR, Curitiba, PR, Brasil \\ 'Departamento de Terapia Ocupacional, Universidade Federal do Paraná - UFPR, Curitiba, PR, Brasil
}

\begin{abstract}
Resumo: A Reforma Psiquiátrica, por meio do processo de desinstitucionalização e criação de serviços substitutivos ao modelo hospitalocêntrico, chamou as famílias para assumirem uma parcela da responsabilidade na atenção à pessoa com transtorno mental. Os familiares passaram a ser parte imprescindível para a sua reinserção social sem, no entanto, receberem treinamento e orientação para isso. Objetivos: Averiguar a contribuição da Terapia Ocupacional no apoio e assistência aos familiares de pessoas com transtornos mentais no contexto da Reforma Psiquiátrica e da desinstitucionalização. Procedimentos metodológicos: A discussão é amparada em uma revisão não sistemática da literatura científica nacional e internacional, utilizando capítulos de livros e artigos científicos. A pesquisa de artigos científicos foi realizada nas bases de dados Bireme e Medline, em publicações do período de 2001 a 2011. Resultados: Constatou-se que ao receber suporte para enfrentar as dificuldades no relacionamento com o familiar com transtorno mental a sobrecarga emocional da família é amenizada e que a Terapia Ocupacional possui um arcabouço teórico bastante significativo no que diz respeito a esse tipo de assistência, derivado de uma prática consistente e que parece pouco explorado. Conclusões: Existe uma lacuna nos serviços, relacionada à elaboração de programas de atendimento às necessidades da família, pois não se pode negar a sobrecarga que a presença do indivíduo com transtorno mental acarreta ao núcleo familiar, especialmente a partir da Reforma Psiquiátrica, e o Terapeuta Ocupacional, por meio de sua prática, pode contribuir de maneira significativa nesse trabalho.
\end{abstract}

Palavras-chave: Terapia Ocupacional, Desinstitucionalização, Família, Transtorno Mental.

\section{Occupational Therapy contributions in the support and assistance to families of people with mental disorders}

\begin{abstract}
The Psychiatric Reform, through the deinstitutionalization process and the creation of substitutive services to the hospitalocentric model, invited families to share part of the responsibility in the care for people with mental disorders. With this change, family members have become essential to the social reintegration of individuals with mental disorders, but without receiving any type of training or orientation on it. Objectives: To investigate the contribution of Occupational Therapy regarding the support and assistance to relatives of people with mental disorders in the context of the Psychiatric Reform and Deinstitutionalization. Methodological Procedures: The discussion presented is based on a non-systematic national and international scientific literature review of book chapters and papers published in the databases Bireme and Medline between 2001 and 2011. Results: It was possible to observe that when the family receives support to deal with the difficulties inherent to the family member with mental disorder, their emotional charge is relieved. It was also found that Occupational Therapy presents a very meaningful theoretical framework concerning this type of assistance, derived from a consistent practice that seems little explored. Conclusions: There is a gap in the services related to the development of programs to attend family necessities, because the burden placed on families of individuals with mental disorder cannot be denied, especially after the Psychiatric Reform, and Occupational Therapy can meaningfully contribute to this work through its practice.
\end{abstract}

Keywords: Occupational Therapy, Deinstitutionalization, Family, Mental Disorder.

Autor para correspondência: Milton Carlos Mariotti, Departamento de Terapia Ocupacional, Universidade Federal do Paraná, Rua Professor Lothario Meissner, 632, Bloco Didático II-Saúde, Jardim Botânico, CEP 80210-170, Curitiba, PR, Brasil, e-mail: mariotti@ ufpr.br

Recebido em Dez. 04, 2012; Revisão em Mar. 21, 2013; Aceito em Jun. 20, 2013. 


\section{Introdução}

A Reforma Psiquiátrica tem como objetivo principal a desinstitucionalizaçáo por meio da desconstrução do manicômio e dos paradigmas envolvidos. Os profissionais de saúde, juntamente com a sociedade, vêm discutindo sobre a substituição progressiva dos manicômios por outras práticas terapêuticas e busca da cidadania do doente mental (GONÇALVES; SENA, 2001). No modelo atual de desinstitucionalização, a família é incluída como parceira no processo de reabilitação da pessoa com transtorno mental. Nesse contexto, os familiares podem contribuir para a efetivação e resolutividade dos serviços substitutivos (SOARES; MUNARI, 2007; PIMENTA, 2008).

Com a ocorrência do transtorno mental surge uma série de situaçôes que envolvem as pessoas do grupo social, especialmente aquelas do convívio familiar (MORASKI; HILDEBRANDT, 2005; COLVERO; IDE; ROLIM, 2004; PEREIRA, 2003). No entanto, embora a família ganhe destaque no processo de tratamento do indivíduo com transtorno mental, nem todas possuem condiçôes para assumir tal responsabilidade (GÓIS; MARTINS; VIEIRA, 2004). Considerando a família como unidade básica de cuidado, é preciso atentar ao que ela necessita. Além dos recursos institucionais disponíveis, existe a necessidade do preparo e do apoio de profissionais. Desse modo, as açôes dirigidas aos familiares de indivíduos com transtorno mental devem se estruturar de maneira a favorecer e potencializar a relação familiar/profissional/serviço, bem como a relaçáo familiar/pessoa com transtorno mental (PEREIRA; PEREIRA JUNIOR, 2003; COLVERO; IDE; ROLIM, 2004).

As famílias são importantes, não importa como são definidas. Elas fornecem um dos contextos chave e pontos de referência para a socialização, pois ajudam a desenvolver as identidades e moldam o comportamento de seus membros em relação aos outros. É no seio das famílias que se aprende a estar no mundo, como se entende e se interage com o mundo e as pessoas ao redor. As famílias fornecem o contexto para a aprendizagem das crenças, valores, atitudes e costumes que norteiam parte da vida dos indivíduos.

Os rituais familiares são uma forma de comunicação simbólica que transmite identidade à família, conferem a seus membros um sentimento de pertencimento e fornecem a continuidade de significado através das geraçōes. As rotinas, por outro lado, são comportamentos padronizados que têm objetivos instrumentais. Ou seja, as rotinas dão ordem à vida, enquanto os rituais dão significado (SEGAL, 2004).

As celebraçôes em família, as tradiçôes familiares, os padrōes e interaçóes, são três tipos de rituais da família. As celebrações familiares sáo rituais simbólicos da família pertencentes a uma cultura específica. Por outro lado, as tradiçóes familiares e as interações padronizadas são exclusivas para cada família. As tradiçôes familiares referem-se a ocasiôes como reuniôes, férias ou aniversários. Essas tradições são construídas pelas próprias famílias, comumente continuando ou baseando-se em tradiçóes das famílias dos pais de origem. Por último, as interaçóes padronizadas ocorrem diariamente e consistem em eventos como o jantar, os rituais na hora de dormir ou a maneira de cumprimentar uns aos outros quando voltam para casa. As interaçôes padronizadas são rituais diários (SEGAL, 2004).

No âmbito da Terapia Ocupacional, deve haver sempre um lugar para a família no processo, bem como no tratamento referente a outras modalidades da área da saúde, e é indiscutível a importância do atendimento às expectativas dos familiares sobre como a pessoa com transtorno mental está agindo, o que esse indivíduo e a família precisam (MATTINGLY; LAWLOR, 2002). Borba, Schwartz e Kantorski (2008) referem que ao receber suporte para enfrentar as dificuldades no relacionamento com a pessoa com transtorno mental e a sobrecarga, a carga emocional da família é amenizada.

A relevância do tema, tanto para o indivíduo com transtorno mental quanto para a família, sociedade e instâncias da atenção à saúde, motivou essa pesquisa de revisão bibliográfica sobre o impacto do transtorno mental na família, bem como sobre a assistência da Terapia Ocupacional aos familiares, permitindo assim uma melhor compreensão sobre esse tema tão pouco abordado na Terapia Ocupacional e de grande importância para uma melhor assistência aos familiares de pessoas com transtornos mentais.

\section{Objetivos}

O objetivo deste trabalho foi revisar a literatura relacionada à Reforma Psiquiátrica e ao transtorno mental no âmbito familiar; descrevendo o impacto da presença do indivíduo com transtorno mental nesse contexto; a sobrecarga dessas famílias; e abordar aspectos relacionados ao apoio e assistência a esses familiares pelo profissional de Terapia Ocupacional. 


\section{Metodologia}

A presente pesquisa foi composta por revisão não sistemática da literatura científica que, segundo Munhoz (1989), refere-se à utilização de livros, revistas, documentos, periódicos, enfim, registros que permitam ao pesquisador conhecer o que já foi estudado sobre o assunto abordado.

Para esta pesquisa foi realizada revisão da literatura científica, incluindo capítulos de livros e artigos científicos, utilizando-se as bases de dados Bireme e Medline, com as palavras-chaves: Terapia Ocupacional, Reforma Psiquiátrica, Família e Transtorno Mental e suas combinaçóes, em português e em inglês. Os materiais selecionados para a elaboração desta pesquisa se referem às publicaçóes do período de 2001 a 2011.

A revisão de literatura e a construção do presente trabalho foram realizadas no período de março de 2011 a agosto de 2012.

\section{Resultados e discussão}

A Reforma Psiquiátrica gerou mudanças no núcleo familiar dos indivíduos com transtornos mentais devido à permanência deles junto à família, evidenciando a importância do apoio e assistência aos familiares com relação à sobrecarga acarretada pelo cuidado à pessoa com transtorno mental, especificando-se a contribuição e as possibilidades de intervençóes da Terapia Ocupacional.

\subsection{Reforma Psiquiátrica: Aspectos gerais}

Durante e após a Segunda Guerra Mundial ocorreram reformulaçôes em relação à assistência psiquiátrica, dando-se início às críticas ao modelo asilar, propondo-se a transformação desse espaço e a possibilidade de desospitalizaçáo das pessoas com transtornos mentais, com o seu retorno à família e à comunidade. $\mathrm{O}$ modelo que privilegiava o espaço asilar como local de intervenção e, consequentemente, a exclusão das pessoas com transtornos mentais do convívio social foi revisto e, assim, surgiram novas propostas e modelos, principalmente na Europa e nos Estados Unidos. Ao longo dos anos, esse processo foi sendo reconhecido e denominado como Reforma Psiquiátrica (MORENO; ALENCASTRE, 2003; RIBEIRO; MACHADO, 2008; MACHADO, 2005).
A inspiração dessa nova proposta vinha da Europa, mais especificamente da França, Inglaterra e, sobretudo, da Itália. Essa experiência, iniciada na década de 1960, teve como princípio básico romper com a lógica segregativa e violenta da instituição psiquiátrica e transformar as relaçóes entre a pessoa com transtorno mental, médico, equipe hospitalar e sociedade (MACHADO, 2005). Já nos Estados Unidos o movimento preconizava que o objeto da psiquiatria náo deveria ser a doença, e sim, a saúde mental (RIBEIRO; OLIVEIRA, 2005).

A partir da década de 1970 surgiu no Brasil um movimento de crítica ao modelo tradicional da assistência psiquiátrica, levando, na década de 1980, ao movimento pela Reforma Psiquiátrica brasileira que, influenciada pelos movimentos da Europa e dos Estados Unidos, ganhou importância política e social (SOARES, 2003; RIBEIRO; OLIVEIRA, 2005).

As açôes da Reforma Psiquiátrica brasileira começaram a ter visibilidade a partir da 1a Conferência Nacional de Saúde Mental e do $2^{\circ}$ Congresso Nacional dos Trabalhadores de Saúde Mental, em dezembro de 1987, ganhando força a partir dos avanços da Reforma Sanitária, sancionada através da Constituição de 1988, e, posteriormente, com o advento do SUS, pela lei 8.080, de 1990 (MACHADO, 2005). Enfim, em 2001, após uma intensa mobilização dos trabalhadores da área da Saúde Mental, dos usuários, dos familiares e da mídia, foi aprovado um substitutivo do senador Sebastiâo Rocha ao texto da lei, resultando na lei 10.216, que regulamenta os direitos da pessoa com transtorno mental em relação ao tratamento, propóe a extinção progressiva dos manicômios, a substituição dos hospitais psiquiátricos por outros recursos assistenciais e regulamenta a internação psiquiátrica compulsória (MACHADO, 2005; RIBEIRO; OLIVEIRA, 2005).

A Reforma Psiquiátrica brasileira, através da criação de novos dispositivos em Saúde Mental, assim como através da inserção das ações de saúde mental na saúde pública, possibilita novas abordagens, novos princípios, valores e olhares às pessoas com transtorno mental, impulsionando formas mais adequadas de cuidado no seu âmbito familiar, social e cultural. Os novos serviços e tratamentos levam em consideração a singularidade e as condiçóes concretas das pessoas que os buscam (HIRDES, 2009; RIBEIRO; MACHADO, 2008).

O trabalho interdisciplinar em Saúde Mental éum dos pressupostos para que a desinstitucionalização seja efetiva, colocando-se permanentemente em questão as diferentes concepçóes e estratégias 
utilizadas pelos profissionais, implicando em transformações profundas nos modos de se pensar e fazer o cuidado (WAIDMAN; ELSEN, 2005; MÂNGIA; MURAMOTO, 2006).

Para a consolidação da Reforma Psiquiátrica é fundamental a construção de uma rede comunitária de cuidados. A articulação em rede dos diversos serviços substitutivos ao hospital psiquiátrico é essencial para a constituição de um conjunto consistente de referências capazes de acolher a pessoa com transtorno mental e seus familiares (BRASIL, 2005).

É necessário preparar também a comunidade para a convivência com a pessoa com transtorno mental, especialmente no que se refere à reconstrução de vínculos. Para isso, é importante o envolvimento de vários segmentos da sociedade, integrando os interesses da populaçấo (famílias, usuários, profissionais e comunidade em geral) e os interesses políticos associados à melhoria da qualidade de vida da populaçáo, com a implantaçáo de leis e decretos que assegurem uma assistência adequada e digna à pessoa com transtorno mental e sua família (WAIDMAN; ELSEN, 2005).

\subsection{Transtorno mental e família}

O adoecimento de um membro da família é considerado um dos agravantes das relaçóes familiares. Esse adoecer acarreta um desequilíbrio entre a demanda de ajustamento e os recursos disponíveis para lidar com a questáo (SOUZA et al., 2001). Independentemente do tipo de família ou de suas características singulares, esse grupo é afetado pela presença da pessoa com transtorno mental em diversos âmbitos: sociais, econômicos e emocionais. Os familiares modificam sua rotina, costumes e valores com os quais estavam até então acostumados a lidar, reestruturando sua vida de forma significativa a fim de se adequarem à presença do doente mental e à desestabilização que ele traz para os familiares (DUARTE, 2008; PIMENTA, 2008). Diante do impacto do transtorno mental no núcleo familiar, a família passa a viver um processo de reorganização de suas dinâmicas (NAVARINI; HIRDES, 2008; PEREIRA; PEREIRA JUNIOR, 2003).

Quando a família compreende o transtorno mental torna-se mais fácil para os familiares terem experiências emocionais positivas em relação à pessoa com transtorno mental (MELLO, 2005). Uma vez que a família, como grupo, lida com os problemas de saúde, não se pode desvincular o indivíduo do meio em que ele vive. Assim, não se pode separar a doença do contexto familiar. Dessa forma, sendo a família um elemento essencial, ela deve ser compreendida como aliada da equipe de saúde, investindo na recuperação do indivíduo com transtorno mental (NAVARINI; HIRDES, 2008).

\subsection{O impacto da Reforma Psiquiátrica na família}

As consequências da Reforma Psiquiátrica refletem-se de forma direta sobre a família, principalmente sobre as pessoas responsáveis pelo cuidado da pessoa com transtorno mental. No contexto da assistência em regime aberto, o indivíduo com transtorno mental é reinserido ou mantido no convívio familiar, sendo o tratamento não mais centrado no hospital psiquiátrico. Assim, espera-se da família uma retomada na responsabilização pelos seus familiares acometidos por transtornos mentais, assumindo um papel importante na reabilitaçáo psicossocial de seu familiar, sendo corresponsável pelo tratamento e cuidado (GONÇALVES; SENA, 2001; PIMENTA, 2008; PEREIRA; PEREIRA JUNIOR, 2003; COLVERO; IDE; ROLIM, 2004; SEVERO et al., 2007; MIELKE et al., 2010).

Nesse sentido, o encargo da família foi aumentado, pois será despertada para solicitações, reivindicações e aportes necessários para o convívio e enfrentamento do transtorno. Os familiares passaram a conviver mais de perto com o indivíduo com transtorno mental, situação que gera dificuldades e sobrecargas de ordem emocional, social, relacional, econômica e material (SOARES, 2003; PEREIRA, 2003; MORENO; ALENCASTRE, 2003; PIMENTA, 2008).

Portanto, o cuidado deve também ser estendido aos familiares, que sofrem consequências ao terem de cuidar de pessoas com transtornos mentais. Assim, é essencial conhecer o universo familiar e como seus integrantes reagem e convivem com a pessoa com transtorno mental (COLVERO; IDE; ROLIM, 2004; BORBA; SCHWARTZ; KANTORSKI, 2008).

\subsection{Sobrecarga familiar}

O conceito de sobrecarga é multidimensional, envolvendo diversos aspectos que interferem na rotina e dinâmica familiar, desorganizando o dia a dia da família (SOARES; MUNARI, 2007). Essa sobrecarga familiar pode ser definida como objetiva e subjetiva. 
A sobrecarga objetiva é identificada com maior intensidade, talvez por ser mais concreta; se refere aos problemas ou dificuldades verificáveis e observáveis causados pelos comportamentos do doente. Ela é entendida como demanda real, imposta pela convivência com a pessoa com transtorno mental. Os encargos objetivos incluem: tempo utilizado para a assistência, redução das relaçóes sociais e do tempo livre, dificuldade econômica e dificuldade quanto ao trabalho.

A sobrecarga subjetiva é abstrata; refere-se aos sentimentos pessoais sobre o ato de cuidar. Ela pode ser definida como sobrecarga ou custo emocional, ou seja, é o sofrimento da família em resposta ao transtorno mental, sendo composta por uma série de emoções que as famílias enfrentam, causadas pelo transtorno mental do familiar, e está relacionada às consequências da sobrecarga objetiva. Os encargos subjetivos acarretam: desenvolvimento de sintomas de ansiedade, efeitos psicossomáticos, sentimentos de culpa, de vergonha, de desorientação quanto às informaçôes sobre o transtorno mental e isolamento social (SOARES; MUNARI, 2007; SOARES, 2003; BORBA; SCHWARTZ; KANTORSKI, 2008; PEREIRA; PEREIRA JUNIOR, 2003).

Os problemas enfrentados pela convivência da família com a pessoa com transtorno mental também podem ser classificados em quatro tipos de sobrecarga impostos aos familiares: financeira, desenvolvimento das rotinas familiares, física e emocional, identificando-se ainda alteraçôes nas atividades de lazer e sociabilidade (PEREIRA; PEREIRA JUNIOR, 2003; MELLO, 2005; PIMENTA, 2008).

A sobrecarga financeira abrange aspectos relacionados à preocupação em suprir as necessidades da casa e do tratamento (compra de medicação, consultas médicas e internaçôes), como também a privação dos demais integrantes da família, em decorrência do orçamento rígido e controlado. Com a presença do indivíduo com transtorno mental no meio familiar, a dificuldade financeira é agravada, pois a família vivencia um processo que exige uma nova estrutura nas relações de trabalho, nas inter-relaçôes e no orçamento familiar. É necessário prever faltas ao trabalho para acompanhar e atender as demandas de cuidados à pessoa com transtorno mental, o que pode comprometer a fonte de renda da família. $\mathrm{O}$ acesso do cuidador ao mercado de trabalho também é limitado, devido às restriçóes de horários disponíveis, bem como pelas oportunidades de emprego perdidas. Ainda, as famílias sofrem privaçóes econômicas por não contarem com um integrante familiar inteiramente produtivo, expressa pela dificuldade de o doente manter vínculo empregatício ou, mesmo, de ingressar no mercado de trabalho (BORBA; SCHWARTZ; KANTORSKI, 2008; NAVARINI; HIRDES, 2008; SOARES, 2003; PIMENTA, 2008).

Em relação ao desenvolvimento das rotinas, a família precisa assumir as atividades domésticas do membro acometido pelo transtorno mental, auxiliar nos cuidados e ausentar-se de atividades para acompanhar a pessoa com transtorno mental. A falta de cooperação do indivíduo nas atividades cotidianas resulta na dependência do familiar cuidador para a realização dessas atividades, o que dificulta a sua participação em outras atividades fora de casa, como lazer e trabalho. Tudo fica comprometido quando a pessoa com transtorno mental náo realiza o que é de sua responsabilidade ou quando, por apresentar comportamento alterado, requer cuidados familiares com sua higiene, alimentação, sono e acompanhamento (MELLO, 2005; SOARES, 2003; PIMENTA, 2008).

A presença da sobrecarga física e emocional é identificada pelo aparecimento de doenças relacionadas ao sistema nervoso, mostrando como os problemas de ordem emocional repercutem sobre a saúde física dos indivíduos. É comum o aparecimento de agravos como gastrite e problemas gastrintestinais, ansiedade, emagrecimento, problemas de coluna, hipertensão arterial, problemas cardíacos, estresse, tensão e nervosismo da família. A sobrecarga em forma de doença física e emocional é ainda constatada pela alteração da dinâmica familiar, pelo aumento das demandas provenientes dessa situação e pela falta de recursos de enfrentamento. Emocionalmente, as pessoas que convivem com a realidade do transtorno mental encontram-se esgotadas, pela privação do sono ou pelo fato de não suportarem mais as implicaçóes que essa convivência gera. A percepção e as dimensões que os cuidadores têm sobre a repercussão do transtorno mental em sua vida contribuem para o desgaste emocional (BORBA; SCHWARTZ; KANTORSKI, 2008; MELLO, 2005).

O provimento de cuidado deveria ser direcionado a ambos, ao cuidador e à pessoa com transtorno mental. Dessa forma, a família necessita de ajuda dos profissionais da Saúde Mental (PEREIRA; PEREIRA JUNIOR, 2003; COLVERO; IDE; ROLIM, 2004). A compreensão dos determinantes da sobrecarga familiar é fundamental aos profissionais de saúde, para uma busca mais assertiva de formas adequadas de atenção à família 
(SEVERO et al., 2007; GONÇALVES; SENA, 2001; SOARES; MUNARI, 2007).

\subsection{Apoio e assistência à família}

No atual contexto da assistência psiquiátrica, a família como protagonista para a prática do cuidado precisa ser inserida de forma efetiva nas discussóes do novo modelo de assistência em Saúde Mental, vista como facilitadora no processo de reinserçáo social da pessoa com transtorno mental (BORBA; SCHWARTZ; KANTORSKI, 2008).

Mais do que uma aliada na efetivação do tratamento, a família deve ser encarada como foco de intervenção, para que seus anseios sejam acolhidos e sua sobrecarga minimizada (BORBA; SCHWARTZ; KANTORSKI, 2008). Assim, os familiares precisam sentir-se preparados para receber a pessoa com transtorno mental em casa, bem como seguros quanto à disponibilidade do serviço de escuta e auxílio na resolução de problemas que venham a ocorrer (COIMBRA et al., 2005; MELLO, 2005).

Dessa forma é preciso considerar a demanda da família, para além da objetividade manifestada em suas queixas, geralmente centradas nos sintomas apresentados pela pessoa com transtorno mental. É imprescindível conhecer a dinâmica familiar e assim estabelecer metas de intervenção a partir da realidade encontrada (PEREIRA; PEREIRA JUNIOR, 2003; BORBA; SCHWARTZ; KANTORSKI, 2008; COLVERO; IDE; ROLIM, 2004; SOUZA et al., 2001).

Acredita-se que os familiares devem ser acompanhados e orientados quanto às reais possibilidades de reabilitação de pessoas com transtornos mentais. A família precisa ter informaçôes sobre a doença, bem como do seu prognóstico, para que se sinta segura e consciente dos problemas que poderão ocorrer (GONÇALVES; SENA, 2001; ROSA; ROSSIGALLI; SOARES, 2010). O componente essencial dessas mudanças é a ajuda aos familiares em relação às formas de enfrentamento da doença, bem como ao entendimento dessa condição. É essencial que eles aprendam não somente a tolerar, mas compreender a realidade em que se encontram (NAVARINI; HIRDES, 2008). É importante que o profissional de Saúde Mental esteja atento às dificuldades da família e possa oferecer suporte para o desempenho de tarefas e decisóes para o cuidado com o familiar, buscando fortalecer as relaçóes que podem produzir saúde (MIELKE et al., 2010; PEREIRA; PEREIRA JUNIOR, 2003).
Dessa forma, os serviços deveriam elaborar programas visando atender as necessidades da família, pois não se pode negar a sobrecarga que a presença do indivíduo com transtorno mental acarreta ao núcleo familiar. É preciso incluir e ofertar a esse núcleo familiar a possibilidade do cuidado (MORENO; ALENCASTRE, 2003; PIMENTA, 2008). É indispensável pensar em redes de apoio que possibilitem ajuda no cuidado.

As questôes que envolvem a saúde mental e a família são complexas e precisam envolver mais de uma disciplina, ou seja, mais de um saber específico. Para se trabalhar com famílias de pessoas com transtornos mentais e obter-se resultados satisfatórios são fundamentais a interdisciplinaridade, a intersetorialidade e o estabelecimento de parcerias com a família e a comunidade. Nos serviços de Saúde Mental a prática da interdisciplinaridade pode representar muitos ganhos na realização do trabalho (WAIDMAN; ELSEN, 2005; SOARES; MUNARI, 2007; FONSECA, 2008).

\subsection{Contribuições da Terapia Ocupacional no apoio e assistência à família}

Por ser uma prática que reúne conhecimentos de diversas disciplinas (saúde, educação social e cultural), a Terapia Ocupacional pode ser um elemento importante na construção de novos caminhos para a atenção à saúde, integral, globalizante e na perspectiva da totalidade, subjetividade e singularidade dos indivíduos. Nesse sentido, o terapeuta ocupacional deve buscar, por meio de sua especificidade, a ampliação do cuidado e a possibilidade de resgate dos direitos de cidadania dos sujeitos (RIBEIRO; OLIVEIRA, 2005; ALMEIDA; TREVISAN, 2011; RIBEIRO; MACHADO, 2008).

No contexto de atenção à família, o terapeuta ocupacional deve estabelecer um programa selecionando, analisando e, se necessário, adaptando atividades que atendam às demandas da pessoa com transtorno mental em si, mas que se fundamente nas possibilidades da família. Também é de sua responsabilidade manter os familiares informados acerca da doença do indivíduo, além de oferecer suporte para que eles exponham suas dúvidas, angústias, temores e incertezas (ROSA; ROSSIGALLI; SOARES, 2010; MATTINGLY; LAWLOR, 2002).

Os terapeutas ocupacionais utilizam várias intervençôes que permitem aos indivíduos 
envolverem-se em ocupaçóes e participar da vida cotidiana. As intervençôes que esses profissionais ofertam podem exigir que os indivíduos e, talvez, toda a sua família, mude sua rotina diária. Esses pedidos podem ser atendidos, acrescentando-se algumas ocupaçóes ou atividades específicas na rotina diária ou alterando-se a forma de execução estabelecida para essas rotinas. Muitos terapeutas sabem, no entanto, que essas alteraçôes não são fáceis de implementar (SEGAL, 2004).

Portanto, a ação terapêutica deve englobar os aspectos práticos, concretos, simbólicos, relacionais e materiais, investindo na complexidade da vida cotidiana da pessoa com transtorno mental e de seus familiares de forma a produzir movimentos capazes de oferecer suportes, proteção e resolução de problemas que contribuam para a superaçáo da realidade enfrentada (RIBEIRO; OLIVEIRA, 2005).

As pessoas aprendem a ser seres ocupacionais através das famílias ou por referência às idéias sobre as famílias, quando elas estão ausentes da vida. Embora existam outras influências sobre a vida, para a maioria das pessoas as famílias continuam a ser importantes durante toda a sua vida, mesmo não estando fisica ou emocionalmente acessíveis. As famílias podem ser uma fonte de apoio, frustração e problemas. Elas são uma cultura universal e um ícone cultural (FITZGERALD, 2004).

Como as famílias são elementos centrais de todas as sociedades e assim vivem todas as pessoas, os terapeutas ocupacionais devem interagir com as famílias e levar suas influências em consideração ao exercer a profissão. As famílias são, de fato, parte do discurso cotidiano dos terapeutas ocupacionais (FITZGERALD, 2004).

Nesse sentido, as famílias não podem ser tratadas como algo separado dessas outras influências e, ao mesmo tempo, as crenças sobre saúde, doença, cura e terapia devem ser consideradas no contexto das famílias e outros grupos sociais (FITZGERALD, 2004).

Todos os terapeutas ocupacionais, especialmente aqueles que trabalham diretamente com as famílias, devem adquirir uma melhor compreensão do conceito de cultura e sua influência sobre eles, seus clientes e todos os aspectos da vida diária e profissional. Esses podem se beneficiar ao engajarem-se em reflexão sobre onde eles aprendem não só sobre seus clientes, mas sobre si mesmos como seres culturais. Além disso, a reflexão pode ser útil para ajudar a identificar melhor as influências culturais no seu próprio comportamento pessoal e profissional, funçóes, valores e atitudes, mais os de seus clientes (FITZGERALD, 2004).

As rotinas familiares são mecanismos para a organizaçáo e coordenação de atividades, para o cumprimento das metas instrumentais em tempo hábil. Elas são comportamentos observáveis que se repetem em intervalos previsíveis. As metas de rotinas são direcionadas a completar uma tarefa, uma atividade ou uma série de atividades. Quando as rotinas são concluídas, elas não deixam impressão duradoura (SEGAL, 2004).

Quando as rotinas evoluem para incluir interaçôes simbólicas e significativas, tornam-se rituais. Quando rituais perdem sua interaçáo simbólica e significativa, por sua vez, tornam-se rotinas (SEGAL, 2004).

Muitas vezes, o que pode parecer uma rotina e um modo de atingir as metas instrumentais também pode ser um ritual, uma forma de transmitir uma sensação de identidade, pertencimento e continuidade através das gerações. Por isso, adaptar o que pode parecer uma rotina simples pode exigir que as famílias mudem e adaptem elementos de expressão e compartilhamento da sua própria identidade. Quando essa é a situação, uma mudança pode ser mais difícil de programar (SEGAL, 2004).

A identidade familiar é definida como o sentido subjetivo da família em sua própria continuidade ao longo do tempo, evolui mantendo sua coerência quando novas ocupaçóes são adicionadas e as antigas, descontinuadas. A identidade de uma família é representada nas histórias familiares relacionada a experiências passadas da família e a seus sonhos de futuro. Dessa forma, os rituais familiares estão relacionados às ocupaçóes e refletem os aspectos da identidade da família (SEGAL, 2004). A identidade da unidade familiar tem uma relação direta com sua saúde. Essa identidade se forma através da negociação e do envolvimento em experiências da vida diária. Assim, a maneira como uma família participa nas rotinas diárias define como a família é e como desempenha um papel fundamental na determinação de sua saúde (SCHEMM, 2003).

As rotinas familiares também se relacionam com a saúde da família, porque elas fornecem: uma força estabilizadora na família, um meio para o desenvolvimento da identidade da família, uma força de proteção, que promove a saúde dos membros da família, e uma medida para assegurar o bem-estar dos membros da família em momentos de estresse (SCHEMM, 2003). 
Nesse sentido, o entendimento de que as rotinas apoiam a saúde da unidade familiar é importante para os profissionais de Terapia Ocupacional.

Os costumes e crenças da família servem como base para as rotinas e para a forma como a família se engaja nelas diariamente. Além disso, os valores da família, as normas que ela tem para situações específicas e as sanções para recompensas e punições influenciam a instituição familiar cotidianamente. Essa fundação oferece estrutura para a família e ajuda a determinar as relaçóes entre seus membros e os papéis que eles desempenham. A família define expectativas para o comportamento que orientam a forma como a família opera (SCHEMM, 2003).

Assim, os profissionais precisam aprender que cada unidade familiar constrói coletivamente seu significado de família. Esse significado vem de como os membros interagem uns com os outros, como compartilham tempo, espaço e experiências de vida e como eles se comunicam sobre essas experiências. Aprender e valorizar as contribuiçôes culturais e étnicas da unidade familiar são maneiras para os terapeutas ocupacionais começarem a fornecer serviços centrados na família (SCHEMM, 2003).

Em suma, os profissionais de Terapia Ocupacional podem fornecer cuidados centrados na família abordando as ocupações significativas da unidade familiar, examinando o seu funcionamento ocupacional e avaliando o significado que a família atribui ao seu envolvimento nas rotinas diárias e rituais significativos. Com uma mudança para essa ênfase, o foco das intervençôes não será mais um aspecto discreto da vida familiar, mas sim dirigido à maneira como a família participa de forma significativa no seu dia (SCHEMM, 2003).

Estas intervençóes poderâo influenciar a forma como essas famílias vivem e ocupam significativamente o seu tempo como uma unidade familiar. Os profissionais de Terapia Ocupacional podem se concentrar em aspectos significativos da ocupação da família e da construção familiar. A intervenção pode destinar-se a facilitar o crescimento da família na sua capacidade de participar e vencer esse desafio ocupacional de ser uma família. Esse foco pode incentivar a família a crescer como uma unidade e desenvolver formas mais eficientes, eficazes e satisfatórias de se adaptar a seu desafio ocupacional de ser uma família. Ao fazer isso, o bem-estar geral das famílias pode melhorar (SCHEMM, 2003).

Os profissionais de Terapia Ocupacional precisam ter em mente a necessidade de ajuda às famílias, para ajudá-las a atender às demandas de cuidado ao doente (SCHEMM, 2003).

É preciso identificar exatamente o que significa fornecer esse cuidado. Além disso, ainda é necessário articular claramente como se tratam as ocupações da unidade familiar, como se medem as mudanças na unidade familiar e o que contribui para que a unidade familiar participe significativamente da vida cotidiana (SCHEMM, 2003).

O desafio do terapeuta ocupacional é colaborar com os indivíduos, sua família e outros membros da equipe para idealizar um programa que se fundamente nos potenciais da família e aborde suas necessidades. Para o seu sucesso, o processo de intervençấo deve ser individualizado para cada família, refletindo seu contexto próprio (MATTINGLY; LAWLOR, 2002; SCHEMM, 2003).

Os princípios básicos do cuidado centrado na família podem auxiliar o terapeuta ocupacional a planejar suas intervençôes e abrangem oito áreas distintas, porém relacionadas. Essas áreas incluem: adotar uma perspectiva de sistemas sociais, colocar a família como uma unidade de intervenção, capacitar as famílias, promover o crescimento da produção de comportamentos ao invés de tratamento dos problemas, focar na identificação das necessidades da família, construir a capacidade da família, fortalecer a rede social da família e expandir papéis profissionais e a forma como os papéis são executados (SCHEMM, 2003).

Esse cuidado não consiste apenas em permitir a presença da família junto ao portador de transtorno mental, mas sim sua inclusão no cuidado, onde os familiares atuam como parceiros efetivos da equipe de saúde, tanto planejando quanto realizando o cuidado. Essa é uma prática fundamentada na informação compartilhada e na colaboração entre a equipe de saúde e a família (MATTINGLY; LAWLOR, 2002).

A intervenção da Terapia Ocupacional possibilita a criação e a potencialização de relações, contextos e lugares que favorecem a escuta e o acolhimento dos familiares. Nessa perspectiva é preciso garantir que a relação terapeuta-família seja construída respeitando a realidade e os valores da família, tendo ela como aliada ativa no processo de tratamento (ROSA; ROSSIGALLI; SOARES, 2010). A partir dos vínculos criados nos espaços de acolhimento e escuta, a família se sente fortalecida para lidar com o transtorno mental e tem a possibilidade de reorganizar seu núcleo familiar de acordo com sua vivência com a doença mental (ROSA; 
ROSSIGALLI; SOARES, 2010). A colaboração é efetiva quando os terapeutas ocupacionais e os membros da família formam relaçóes que fomentam uma compreensão compartilhada das necessidades, esperanças, expectativas e contribuiçóes de todos os parceiros (MATTINGLY; LAWLOR, 2002).

Nesse contexto, o terapeuta ocupacional deve compreender os significados das intervençôes, os sentidos da doença na vida do indivíduo e da família e os sentimentos que acompanham essas experiências. À medida que os profissionais descobrem meios de conhecer os familiares e de compreender suas perspectivas surgem novas oportunidades para a construção de experiências mais significativas. Quanto mais significativa for a experiência, maior a probabilidade de que o tratamento seja eficaz (MATTINGLY; LAWLOR, 2002; SCHEMM, 2003).

Para que a família se sinta amparada e fortalecida é necessário que as intervençôes e os suportes a ela garantidos envolvam questóes de informaçáo, base para aumentar a capacidade emocional, escuta de questôes particulares, dentre outras. É necessário que o sistema de saúde e todos os dispositivos que abrangem a assistência ao indivíduo com transtorno mental também estejam preparados para receber e dar suporte aos familiares (PIMENTA, 2008).

Assim, pressupóe-se que a carga emocional da família e do indivíduo com transtorno mental seria diminuída através do envolvimento deles, dando-se suporte para o enfrentamento das dificuldades relacionadas ao transtorno mental, da sobrecarga, da culpa, do isolamento social, da carência de informaçóes, dos problemas de vínculo com os profissionais de saúde, das situaçôes de crise, emergência e conflitos familiares, aumentando o nível de interação e empatia da família com seu familiar com transtorno mental (COIMBRA et al., 2005).

A área de Saúde Mental, na Terapia Ocupacional, é uma das áreas com número expressivo de profissionais, no entanto necessita do desenvolvimento de pesquisas e relatos sobre as práticas desenvolvidas (WACHHOLZ; MARIOTTI, 2009). Salientamos que essa necessidade se estende, de maneira especial e contundente sobre as práticas desenvolvidas com familiares, devido a sua grande importância.

\section{Conclusão}

Considerando o aumento da responsabilidade da família no cuidado ao indivíduo com transtorno mental e o impacto que essa situação gera no núcleo familiar, destaca-se a necessidade de inclusão dos familiares na avaliaçáo e no planejamento das ações efetuadas pelos serviços de Saúde Mental, objetivando aumentar a qualidade dos serviços e a satisfação dos usuários e seus familiares, assim como diminuir a sobrecarga sentida por esses familiares. É preciso que os profissionais forneçam informações aos familiares sobre a doença do indivíduo, sobre os medicamentos prescritos e o tratamento oferecido ao portador de transtorno mental. Estratégias para lidar com a pessoa com transtorno mental no dia a dia e nos momentos de crise devem igualmente ser fornecidas pelos profissionais, além do apoio nas dificuldades enfrentadas. É fundamental considerar que a família é formada por um sistema de valores, crenças, conhecimentos e práticas que direcionam suas ações, pois a compreensão da dinâmica familiar e da função que a doença assume na família é determinante no tratamento das manifestaçóes do transtorno mental. O cuidado é o elemento principal para a transformação do modo de viver e do sofrimento do indivíduo com transtorno mental e de sua família no cotidiano. Portanto, os profissionais de saúde precisam desenvolver estratégias de inserção da família no cuidado. Esse cuidado deve envolver espaços de escuta, acolhimento, construção e manutenção do vínculo entre equipe e família, demonstrando que esses profissionais valorizam a participação da família e entendem a importância de ela ser assistida em suas necessidades. O terapeuta ocupacional, por meio de sua prática, pode contribuir de maneira significativa nesse trabalho. O desafio do terapeuta ocupacional é colaborar com os indivíduos, sua família e outros membros da equipe para idealizar um programa que se fundamente nos potenciais da família e aborde suas necessidades. Para o seu sucesso, o processo de intervenção deve ser individualizado para cada família, refletindo seu contexto próprio.

\section{Referências}

ALMEIDA, D. T.; TREVISAN, E. R. Estratégias de intervenção da Terapia Ocupacional em consonância com as transformações da assistência em saúde mental no Brasil. Interface - Comunicação, Saúde, Educação, Botucatu, v. 15, n. 36, p. 299-307, 2011.

BORBA, L. O.; SCHWARTZ, E.; KANTORSKI, L. P. A sobrecarga da família que convive com a realidade do transtorno mental. Acta Paulista de Enfermagem, São Paulo, v. 21, n. 4, p. 588-594, 2008. http://dx.doi. org/10.1590/S0103-21002008000400009

BRASIL. Ministério da Saúde. Reforma Psiquiátrica e politica de saúde mental no Brasil. Brasília, 2005. (Documento apresentado à Conferência Regional de Reforma dos Serviços de Saúde Mental : 15 anos depois de Caracas). Disponível em: <http://portal.saude.gov. 
br/portal/arquivos/pdf/relatorio_15_anos_caracas.pdf $>$. Acesso em: 10 maio 2011.

COIMBRA, V. C. C. et al. Reabilitação Psicossocial e família: consideraçôes sobre a reestruturação da assistência psiquiátrica no Brasil. Revista Eletrônica de Enfermagem, Goiânia, v. 7, n. 1, p. 99-104, 2005.

COlVERO, L. A.; IDE, C. A. C.; ROlim, M. A. Família e doença mental: a difícil convivência com a diferença. Revista da Escola de Enfermagem da USP, São Paulo, v. 38, n. 2, p. 197-205, 2004.

DUARTE, R. A. [Re] tratando a familia: Reflexos e reflexôes sobre família e saúde mental. 2008. 175 f. Dissertação (Mestrado em Educação, Cultura e Organizaçóes Sociais)-Fundação Educacional de Divinópolis, Universidade do Estado de Minas Gerais, Belo Horizonte, 2008. Disponível em: <http://www. funedi.edu.br/files/mestrado/Dissertacoes/TURMA3/ DissertacaoRonaldoAlvesDuarte.pdf $>$. Acesso em: 11 maio 2011.

FITZGERALD, M. H. A dialogue on Occupational Therapy, culture and families. The American Journal of Occupational Therapy, Bethesda, v. 58, n. 5, p. 489-498, 2004. http://dx.doi.org/10.5014/ajot.58.5.489

FONSECA, M. A. A prática do terapeuta ocupacional em Saúde Mental a partir de uma perspectiva não excludente e de respeito às diferenças. In: DRUMMOND, A. F.; REZENDE, M. B. Intervençôes da Terapia Ocupacional. Belo Horizonte: Editora UFMG, 2008. p.71-94.

GÓIS, C. C.; MARTINS, G. L.; VIEIRA, M. G. A importância da participação e acompanhamento da família no processo de tratamento do portador de transtorno mental. 2004. 67 f. Monografia (Bacharelado em Serviço Social)Faculdades Integradas "Antonio Eufrásio de Toledo", Faculdade de Serviço Social de Presidente Prudente, Presidente Prudente, 2004. Disponível em: <http:// intertemas.unitoledo.br/revista/index.php/Juridica/ article/view/587/601>. Acesso em: 04 maio 2011.

GONÇALVES, A. M.; SENA, R. R. A Reforma Psiquiátrica no Brasil: Contextualização e reflexos sobre o cuidado com o doente mental na família. Revista Latino-Americana de Enfermagem, Ribeirão Preto, v. 9, n. 2, p. 48-55, 2001.

HIRDES, A. A Reforma Psiquiátrica no Brasil: uma (re) visão. Ciência \& Saúde Coletiva, Rio de Janeiro, v. 14, n. 1, p. 297-305, 2009.

MACHADO, K. Como anda a Reforma Psiquiátrica? Radis Comunicação em Saúde, Rio de Janeiro, n. 38, p.11-14, 2005.

MÂNGIA, E. F.; MURAMOTO, M. Integralidade e construção de novas profissionalidades no contexto dos serviços substitutivos de saúde mental. Revista de Terapia Ocupacional da Universidade de São Paulo, São Paulo, v. 17, n. 3, p. 115-122, 2006.

MATTINGLY, C. F.; LAWLOR, M. C. A experiência da incapacidade na perspectiva da família. In: NEISTADT, M.; CREPEAU, E. B. Terapia Ocupacional: Willard \& Spackman. 9. ed. Rio de Janeiro: Guanabara Koogan, 2009. p.37-45.
MELLO, R. A construção do cuidado à família e a consolidação da Reforma Psiquiátrica. Revista Enfermagem UERJ, Rio de Janeiro, v. 13, n. 3, p. 390-395, 2005.

MIELKE, F. B. et al. A inclusão da família na atenção psicossocial: uma reflexão. Revista Eletrônica de Enfermagem, Goiânia, v. 12, n. 4, p. 761-765, 2010.

MORASKI, T. R.; HILDEBRANDT, L. M. As percepçóes de doença mental na ótica de familiares de pessoas psicóticas. Revista Eletrônica de Enfermagem, Goiânia, v. 7, n. 2, p. 195-206, 2005.

MORENO, V.; ALENCASTRE, M. B. A trajetória da família do portador de sofrimento psíquico. Revista da Escola de Enfermagem da USP, São Paulo, v. 37, n. 2, p. 43-50, 2003. http://dx.doi.org/10.1590/ S0080-62342003000200006

MUNHOZ, D. G. Economia aplicada: Técnicas de pesquisa e análise econômica. Brasília: UNB, 1989.

NAVARINI, V.; HIRDES, A. A família do portador de transtorno mental: identificando recursos adaptativos. Texto \& Contexto Enfermagem, Florianópolis, v .17, n. 4. p. 680-688, 2008.

PEREIRA, M. A. O. Representação da doença mental pela família do paciente. Interface - Comunicação, Saúde, Educação, Botucatu, v. 7, n. 12, p. 71-82, 2003.

PEREIRA, M. A. O.; PEREIRA JUNIOR, A. Transtorno mental: dificuldades enfrentadas pela família. Revista da Escola de Enfermagem da USP, São Paulo, v. 37, n. 4, p. 92-100, 2003.

PIMENTA, E. S. A relação das famílias no tratamento dos portadores de transtorno mental realizado no centro de atenção psicossocial: Uma perspectiva institucionalista. 2008. 119 f. Dissertação (Mestrado em Psicologia)Pontifícia Universidade Católica de Minas Gerais, Belo Horizonte, 2008. Disponível em: <http://www. pucminas.br/documentos/dissertacoes_eliane_souza. pdf>. Acesso em: 11/05/2011.

RIBEIRO, M. B. S.; OLIVEIRA, L. R. Terapia Ocupacional e Saúde Mental: construindo lugares de inclusão social. Interface - Comunicação, Saúde, Educação, Botucatu, v. 9, n. 17, p. 425-431, 2005.

RIBEIRO, M. C.; MACHADO, A. L. A Terapia Ocupacional e as novas formas do cuidar em saúde mental. Revista de Terapia Ocupacional da Universidade de São Paulo, São Paulo, v. 19, n. 2, p. 72-75, 2008.

ROSA, S. D.; ROSSIGALLI, T. M.; SOARES, C. M. Terapia Ocupacional e o contexto familiar. Cadernos de Terapia Ocupacional da UFSCar, São Carlos, v. 18, n. 1, p. 7-17, 2010.

SCHEMM, R. Occupation-Based and Family-Centered Care: A challenge for current practice. The American Journal of Occupational Therapy, Bethesda, v. 57, n. 3, p. 347-350, 2003. http://dx.doi.org/10.5014/ajot.57.3.347

SEGAL, R. Family routines and rituals: A context for Occupational Therapy Interventions. The American Journal of Occupational Therapy, Bethesda, v. 58, n. 5, p. 499-508, 2004. http://dx.doi.org/10.5014/ajot.58.5.499 
SEVERO, A. K. S. et al. A experiência de familiares no cuidado em saúde mental. Arquivos Brasileiros de Psicologia, Rio de Janeiro, v. 59, n. 2, p.143-155, 2007.

SOARES, C. B. Família e desinstitucionalização: Impacto da representação social e da sobrecarga familiar. 2003. 161 f. Dissertação (Mestrado em Psicologia)-Universidade Católica de Goiás, Goiânia, 2003. Disponível em: <http://tede.biblioteca.ucg.br/ tde_arquivos/11/TDE-2006-11-23T140846Z-238/ Publico/Carlene\%20Borges\%20Soares.pdf>. Acesso em: 04 maio 2011.

SOARES, C. B.; MUNARI, D. B. Consideraçóes acerca da sobrecarga em familiares de pessoas com transtornos mentais. Ciência, Cuidado e Saúde, Maringá, v. 6, n. 3, p. 357-362, 2007.
SOUZA, R. C. et al. Projeto Terapêutico na atenção em psiquiatria: a importância da inserção familiar. Acta Paulista de Enfermagem, São Paulo, v. 14, n. 3, p. 80-86, 2001.

WACHHOLZ, S. M. S.; MARIOTTI M. C. A participação do Terapeuta Ocupacional na Reforma Psiquiátrica e nos novos serviços de Saúde Mental. Cadernos de Terapia Ocupacional da UFSCar, São Carlos, v. 17, n. 2, p. 147-159, 2009.

WAIDMAN, M. A. P.; ELSEN, I. O cuidado interdisciplinar à família do portador de transtorno mental no paradigma da desinstitucionalização. Texto \& Contexto Enfermagem, Florianópolis, v. 14, n. 3, p. 341-349, 2005.

\section{Contribuição dos Autores}

Roberta Pereira Casagrande: Elaboração do Projeto, Revisão de literatura nas bases de dados, concepção do texto e redação. Milton Carlos Mariotti: Orientação do Projeto e da elaboração e revisão do texto. Mônica de Macedo Cardoso: revisão do texto. 